\title{
Spatial Heterogeneity of Soil Mite Community and its Spatial Relationship with Environmental Factors in Maoer Mountains
}

\author{
Limei Zhang ${ }^{1,2,5}$,Lingjun Meng ${ }^{1,6}$, Chuanwei Guo ${ }^{1,3}$, Meixiang Gao ${ }^{1,2}$, Dong Liu ${ }^{4}$ \\ and Xueping Zhang ${ }^{1,2}$ \\ 1. Geographical Sciences College, Harbin Normal University, Harbin 150025; \\ 2. Key Laboratory of Remote Sensing Monitoring of Geographic Environment, \\ College of Heilongjiang Province, Harbin Normal University, Harbin 150025, \\ China; 3. Urban Planning \& Architectural Design Institute of Fudan University, \\ Shanghai 200433, China; \\ 4. Key Laboratory of Wetland Ecology and Environment, Northeast Institute of \\ Geography and Agroecology, Chinese Academy of Sciences, Changchun 130012, \\ China; \\ 5. School of History Culture \& Tourism Heilongjiang University, Harbin 150080, \\ China; 6.School of Continuing Education, Heilongjiang University, Harbin \\ 150080, China \\ * Meixiang GAO Email: gmx102@163.com.
}

\begin{abstract}
Maoer Mountain National Forest Ecological Station is located in Heilongjiang Province. By using the statistical spatial analysis method, which showed that the soil mites community and species richness of mites spatial heterogeneity. Also, which is illustrated that the spatial effect relationship with the environmental factors. The results of crossvariogram and simple Mantel test showed that positive relationships between soil mite communities, specific mite species and environmental factors were detected. Among the environmental factors, soil $\mathrm{pH}$ showed significant affects on spatial heterogeneity of soil mite species in both years. When considering the relationships between soil mite species, positive correlations and specific mite species were also observed. Spatial heterogeneities of soil mite communities and most of the soil mite species were regulated by structured factors, in which environmental variables might be important drivers. Thus, it is implied that abundances of soil mite community and most of the soil mite species showed aggregated spatially heterogeneity, and significant relationship between such heterogeneity and environmental factors were detected.
\end{abstract}

Keywords: Spatial heterogeneity; Spatial relationships; Geostatistics; Soil mite community; Maoer Mountains.

\section{Introduction}

Soil animal community ecology is devoted itself to reveal the regulatory mechanism of soil animals spatial distribution pattern(Jiménez et al., 2011). Soil animals form community colony in multiple measure, however, we cannot clear that the reason of forming and regulatory mechanism of spatial pattern. The variable biology and non-living things, which are deemed to a significant regulatory factor(Jiménez et al., 2011). All of them state that these factors on spatial patterns of soil animal community and species coexistence of regulation function has always been the focus of community ecology(Gutiérrez-López et al., 2010). Analysis the soil animals community of spatial heterogeneity and illustrate the spacial relationship of soil animals between environmental 
factors and soil animals, which is one of the most important basis and shows the scientific problems.

Spatial heterogeneity of soil animals community is identified to noise, which hinder soil animals actuating the research of ecological process. At present, it is widely believed that spatial heterogeneity is crux to understand the structure and function of soil biodiversity(Ettema et al., 2002). Soil mites, which are one of the most important biological components of biological underground ecosystem. The animals which lived in this place have smaller and weaker ability of activity than others(Ojala et al., 2001). It is considered to be an crucial target for researching the underground ecosystem pattern and the process of relationship. This research showed that soil mite community have spatial auto-correlation, which was manifested to clustering character(Gao et al., 2014). Related research on farm ecosystem was discussed that the relationship between soil mites and environmental factors in space function on the surface or underground(Gao et al., 2015). But also having forest ecological system which was based on small scale space relationship between the soil mites and environmental factors(Ingimarsdóttir et al., 2012; Minor et al., 2011). As we know, this study depended on the method of statistical analysis, in order to researching the soil mites community and the spatial heterogeneity of mites species. Analysing the different species of mites in soil mites community, environmental factors and the space interaction relationship. In the present study, the soil animal community structure, the process and mechanism of species coexistence research established the foundation in the space interaction relationship.

\section{Materials and Methods}

\subsection{Introduction of Study Area}

This study was conducted at the Maoer mountain forest ecosystem $\left(\begin{array}{ll}127^{\circ} & 30^{\prime} \sim 127^{\circ}\end{array}\right.$ $34^{\prime} \mathrm{E}, 45^{\circ} 20^{\prime} \mathrm{N} \sim 45^{\circ} 25^{\prime} \mathrm{N}$ ), which is located in the northeastern of Heilongjiang province with a continental monsoon climate. The climate of this area is warm and humid in summer, but cold and dry climate in winter. The temperature is about 3.1 degree annually, precipitation and evaporation is $629 \mathrm{~mm}$ and $864 \mathrm{~mm}$, respectively. Vegetation was obtained in the Chang Bai flora, experimental sample was set in deciduous broad leaf forest which is more than sixty years old. The main layer of it is about 18 meter, average elevation is 400 meter, average gradient is 15 degree and the soil is typical dark brown soil. There are many kinds of ground vegetation, which include Corylus mandshurica, Ulmus pumila, Rhamnus diamantiaca, Padus avium, Betula platyphylla, Syringa oblata, Filipendula palmata, Urtica angustifolia, Aegopodium alpestre, Maianthemum bifolium and Brachybotrys paridiformis.

\subsection{Field Sampling}

Soil sample at the $50 \times 50 \mathrm{~m}^{2}$ high were taken from the land randomly, which was composed of one hundred $5 \times 5 \mathrm{~m}^{2}$ small square samples, totally 121 grid nodes. In August 2012, we regarded the intersection of lower left grid lines as center in each small square samples. Within the area of a radius of $30 \mathrm{~cm}$, excavating an earth volume, which size was $20 \mathrm{~cm} \times 20 \mathrm{~cm} \times 10 \mathrm{~cm}$. Returned to the indoor, using the electronic scales to quantify the small square sample to $500 \pm 5 \mathrm{~g}$. Then, extracted soil mite community by using Tullgren dry funnel. After separating, identified the species and counting the numbers with microscopic. At the same time, taken a soil column, $10 \mathrm{~cm} \times 10 \mathrm{~cm} \times 10 \mathrm{~cm}$, next to each small soil animals sample. In the meanwhile, harvested the litter which in the sampling spots. Repeated sampling in August 2013, used soil auger $(6 \mathrm{~cm}$ inner diameter, depth of $10 \mathrm{~cm}$ ) to dig soil animals and soil samples, which was based on the same method, and investigated the litter samples at the same time. 


\subsection{Analysis of Data}

Soil mites were identified to species and distinguished to the family members(Krantz et al., 2009; Walter et al., 2001). Only will mature mites used for data analysis. Acquiring the PH of soil, water content of soil, moisture content of litter, dry weight of litter and data of soil organic matter. Sum up soil mite community and environment factors whether existed the spatial clustering or not by using the method of Global Morans' $I$. The range of Moran's $I$ was from -1 to 1 , and 0 was represented of in-existence spatial autocorrelation. Greater than zero for positive correlation, on the contrary for negative correlation. By using the method of standard normal deviation to inspect the remarkable extent of expected deviation value. Based on the formula of half variance function to calculate the richness of soil animal community and the variation function value of environmental factors. The value of gold nugget is proportion to the value of drill base $\left[\left(C_{0} /\left(C_{0}+C\right)\right)\right]$ random part, which illustrated that the spatial heterogeneity of the ratio of total variation. Analysis the spatial correlation between soil animals and environmental factors by using Cross covariance function(Crossvariogram). Also, analysis the statistical significance between soil animal richness and environmental factors. Used Ordinary Kriging gained the optimal unbiased valuation in the area where was not regionalized the sample point, and obtained the simulation diagram of spatial differentiation(Wang et al., 1999). Moran's $I$, half variance, cross variance function, Simple Mantel test and Ordinary Kriging interpolation were implemented by Geoda 1.0.0, GS+9.0, R software and Arcgis 10.0 .

\section{Results}

\subsection{Spatial Heterogeneity Characteristics among Soil Mite Community, Species of Mite and Environmental Factors}

3.1.1. Spatial Heterogeneity of Soil Mite Community Richness: 15474 and 9709 individuals were gained in August 2012 and 2013 respectively, which belonged to 19 and 18 species. There were significant global spatial correlation of soil mite community. Its spatial differentiation all could use the spherical model fitting, variation of $7.76 \mathrm{~m}$ and 9.25m respectively. $\left[\left(C_{0} /\left(C_{0}+C\right) \%\right)\right]$ between $25-75 \%$ in 2012 , but less than $25 \%$ in 2013 (Figure1). Ordinary Kriging interpolation showed that mite community space differentiation plaque was obvious (Fjgure 2).
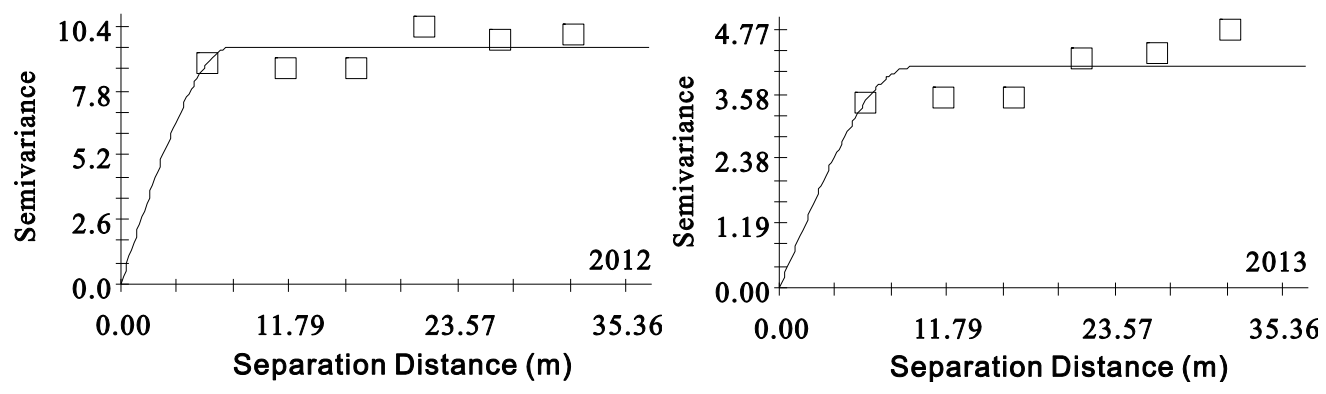

Figure 1. Semivariograms of Soil Mite Communities 

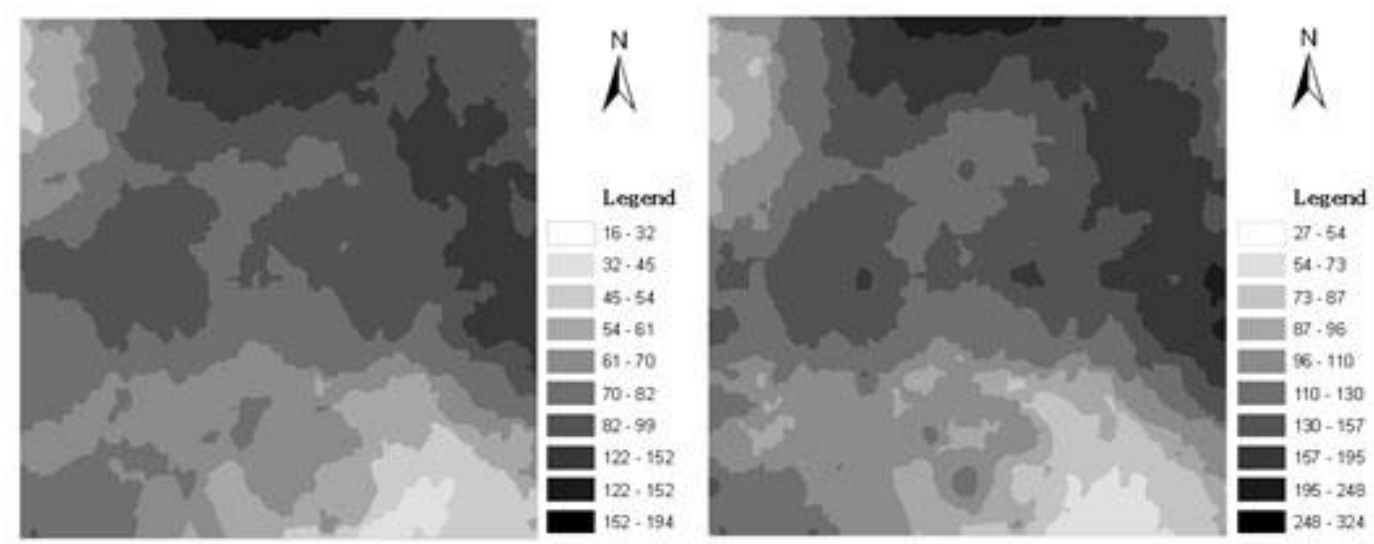

\section{Figure 2. Results of Ordinary Kriging of Soil Mite Community Abundances in 2012 and 2013 (Ind.)}

3.1.2. Spatial Heterogeneity of Soil Mite Species Richness: There were 4 and 3 species richness theory for linear model in 2012 and 2013 respectively, other species in the two years conducted model fitting among index, globular and gaussian.The variation of different species of mites were form 5.58 to 15.28 and from 5.26 to 15.24 in 2012 and 2013 respectively. Most species $(\mathrm{C} 0 /(\mathrm{C} 0+\mathrm{C}) \%)$ in two years between $25 \%$ and $75 \%$, however, the small number of species of value was less than $25 \%$. According to a global Moran's I, Epicriidae sp. and his colleagues were illustrated that there were eleven species of significant global spatial auto-correlation. But since 2013, there were only five species showed that the significant cluster distribution (table 1). Ordinary Kriging interpolation showed that species richness of mites plaque characteristics of spatial differentiation is obvious.

Table 1. Theoretical Models and Corresponding Parameters for Semivariograms in Abundances of Different Soil Mite Species in 2012

\begin{tabular}{lllllllll}
\hline Species & $C_{0}$ & $C_{0}+C$ & $C_{0}\left(C_{0}+C\right) \%$ & Range & Model & $R^{2}$ & $R S S$ & $I$ \\
\hline Macrocheles sp. & 0.66 & 1.87 & 35.08 & 7.59 & Exponential & 0.26 & 0.09 & 0.07 \\
Pachyseius sp. & 0.14 & 2.15 & 15.3 & 5.58 & Exponential & 0.50 & $<0.001$ & 0.04 \\
Epicriidae sp. & 0.51 & 1.29 & 26.8 & 8.37 & Gaussian & 0.28 & $<0.001$ & $0.30^{* * *}$ \\
Gamasolaelaps sp. & 0.85 & 2.87 & 29.16 & 10.32 & Spherical & 0.56 & $<0.001$ & $0.22^{* *}$ \\
Nanhermannia sp. & 0.37 & 1.56 & 23.72 & 6.58 & Exponential & 0.91 & 0.06 & $0.01^{* *}$ \\
Eulohmannia sp. & 0.00 & 0.01 & 25.6 & 7.64 & Spherical & 0.30 & 0.03 & $0.21^{* *}$ \\
Belba sp1. & 0.58 & 2.69 & 21.65 & 9.64 & Gaussian & 0.39 & 0.87 & -0.06 \\
Scheloribates sp. & 2.78 & 2.78 & 100 & -- & Linear & 0.53 & 0.1 & 0.07 \\
Suctobelbella sp. & 1.28 & 2.87 & 44.60 & 10.20 & Spherical & 0.28 & 0.63 & $0.28^{* * *}$ \\
Geholaspis sp. & 0.68 & 2.87 & 23.69 & -- & Linear & 0.57 & 0.94 & 0.06 \\
Protoribates sp. & 1.03 & 1.03 & 100 & -- & Linear & 0.30 & 0.13 & $0.12^{*}$ \\
Oribatida sp. & 1.08 & 1.95 & 55.38 & 8.67 & Exponential & 0.33 & 0.52 & $<0.001$ \\
Acrotritia sp. & 1.26 & 2.64 & 47.72 & 15.28 & Exponential & 0.24 & 0.41 & $0.17^{* * *}$ \\
Prostigmata sp. & 1.38 & 2.78 & 49.64 & 7.61 & Spherical & 0.49 & 0.33 & $0.13^{*}$ \\
Ceratozetes sp. & 0.06 & 0.06 & 11.3 & 6.2 & Exponential & 0.42 & $<0.001$ & 0.07 \\
Holaspulus sp. & 0.16 & 3.03 & 5.3 & 9.88 & Exponential & 0.38 & 0.75 & $0.22^{* *}$ \\
Belba sp2. & 0.38 & 1.26 & 30.16 & 8.65 & Spherical & 1.03 & 0.76 & $0.19^{* *}$ \\
Hypochthonius sp. & 0.7 & 1.59 & 44.03 & 8.48 & Gaussian & 1.30 & $<0.001$ & $<-0.001$ \\
Trombidiidae sp. & 0.79 & 0.79 & 100 & -- & Linear & 0.07 & $<0.001$ & $0.19^{*}$ \\
\hline
\end{tabular}

3.1.3. Spatial Heterogeneity of Environmental Factors: The PH of soil, water content of soil and dry weight of litter were matched by using index and spherical model, the optimal fitting model of soil organic matter were linear. Litter moisture content were fitted by spherical and exponential model in 2012 and 2013, respectively. And the variation of litter moisture content was minimum in both years. The largest variation of 
soil PH in 2012 and the largest variation of soil water content in 2013. In 2013,the soil moisture content $[(\mathrm{C} 0 /(\mathrm{C} 0+\mathrm{C}) \%)]$ was less than $25 \%$ but the ratio of other environmental factors were greater than $75 \%$ (table 2). Ordinary Kriging interpolation space showed that environmental factors manifest the obvious plaque distribution pattern.

Table 2. Theoretical Models and Corresponding Parameters for Semivariograms of Environmental Factors in 2012

\begin{tabular}{llllllll}
\hline $\begin{array}{l}\text { Environmental } \\
\text { factor }\end{array}$ & $C_{0}$ & $C_{0}+C$ & $C_{0} / C_{0}+C \%$ & Range & Model & $R^{2}$ & $R S S$ \\
\hline pH & $<0.001$ & 0.006 & 97.2 & 19.77 & Exponential & 0.92 & $<0.001$ \\
SOM & 4384.5 & 5219.53 & 16 & -- & Linear & 0.69 & 139432 \\
SWC & 0.003 & 0.032 & 91 & 12.63 & Exponential & 0.69 & $<0.001$ \\
LWC & $<0.001$ & 0.032 & 98.9 & 9.94 & Spherical & 0.63 & $<0.001$ \\
LDW & $<0.001$ & 0.006 & 90 & 15.23 & Spherical & 0.90 & $<0.001$ \\
\hline
\end{tabular}

pH-soil pH, SOM-soil organic matter content (g kg-1), SWC-soil water content (w/w\%), LWC-litter water content (w/w\%), LDWlitter dry weight (g sample-1).

\subsection{Soil Mite Community and Mites Spatial Correlation between Species Richness and Environmental Factors}

Soil mite community had the positive spatial correlation with dry weight of litter, moisture content of litter and organic matter of soil in the 5.99 meters and 31.56 meters. Nevertheless, had the negative spatial correlation with PH of soil in the 21.13 meters, but in other dimensions space with a positive correlation. Having the positive spatial correlation of soil moisture content in 11.52 meters and 16.44 meters, in other dimension is negative space relevance (figure 3). Richness and environmental factors of soil mite community had a positive or negative spatial correlation in different scales, respectively.

LDW - Abundance

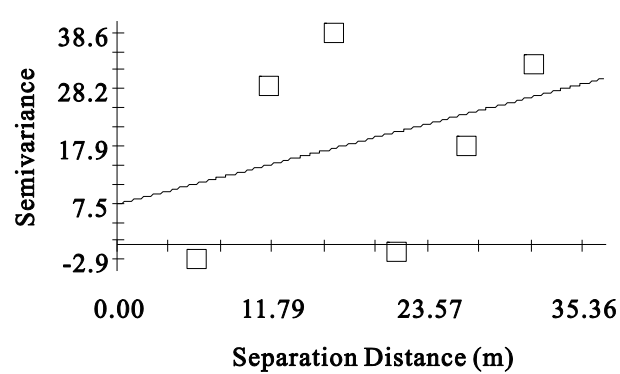

pH - Abundance

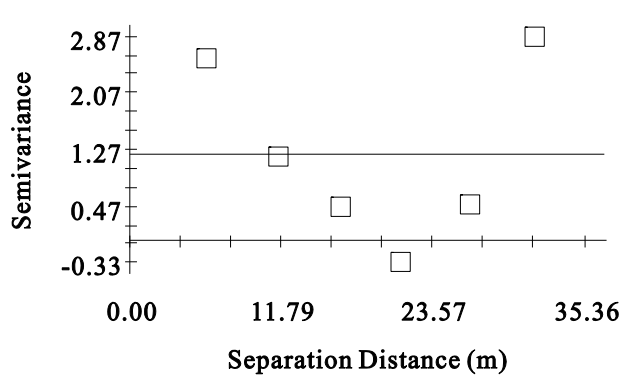

LWC - Abundance

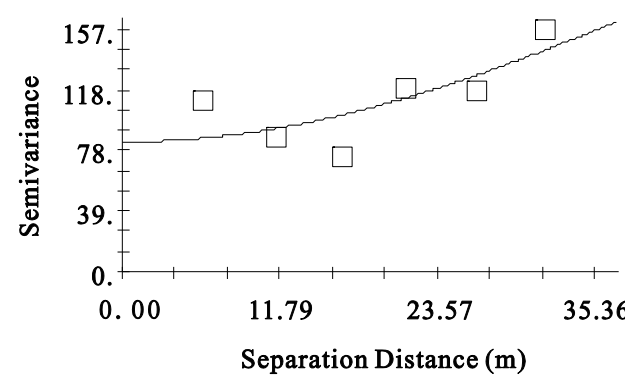

SOM - Abundance

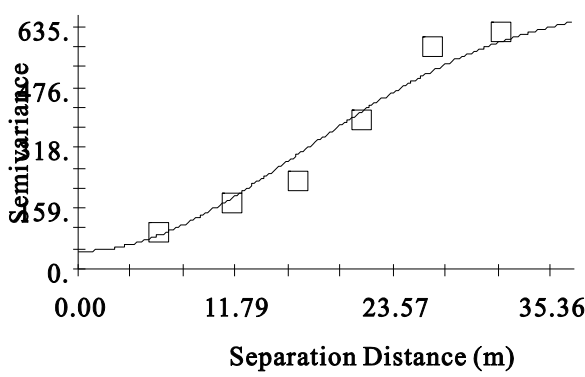




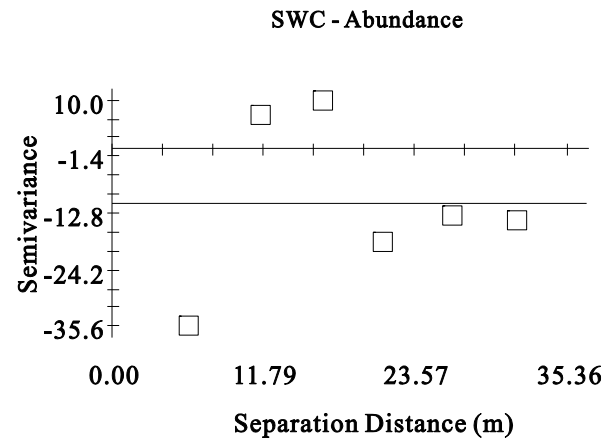

Figure 3. The Spatial Relationships between Soil Mite Abundances and Environmental Factors in 2012

In 2012 and 2013, soil physical and chemical properties had a negative or positive correlation of soil mites richness in a variety of scale space. Mantel simple test showed that the soil PH value have space correlation significantly with soil mite community richness and five species mites, however other soil physical and chemical properties had significant spatial correlation with fewer species respectively. Cross semivariance function showed that the relationship of space interaction among most species in multiple scales, and only a minority of the multiple dimensions of negative space function relationship between species. Mantel simple test showed that there were 23 and 21 species of space had significant positive effect in 2012 and 2013, respectively.

\section{Discussion}

From 2012 to 2013, soil mite community richness had obvious spatial auto-correlation, which was the spatial heterogeneity for the cluster and formed plaques and pore pattern distribution. Value of $\left[\left(C_{0} /\left(C_{0}+C\right) \%\right)\right]$ demonstrated that soil mite community space differentiation was regulated by structural and random factors, which suggested that the process of randomness and certainty were playing an important role in it(Gao et al., 2014). The spatial differentiation was controlled by structural factors mainly, which declared that the process of certainty played an vital role.

There were different manifestation in spatial heterogeneity of different species of mites. Existing the discrepancy in best fitting model of different species for spatial differentiation. Geholaspis sp. and Protoribates sp. were fitted by available linear model in the two years annually, which was characterized as pure nugget effect. In the scale of this study, there were two kinds of mites, which were showed unapparent spatial autocorrelation. Therefore, we should increase the density of sampling in the further. Other species in spatial variation is fitted by using Index, Globular and Gaussian model, all of them were performed a certain structural features. Secondly, there were dynamic characteristics in the same species for the best fitting of mites space differentiation model. In addition to the performance of pure nugget effect species, about a half species perform dynamic change in the species best fitting model of spatial differentiation. Once again, most species in the filed of this study had obvious spatial auto-correlation. However, in the space of 5 to 16 meters within a spatial cluster formation, which showed the dynamic stability of the relative. And most species of mites space differentiation was controlled by structural and random factors, a few of which was regulated by structural factors.

Environmental factors had spatial heterogeneity obviously, but spatial differentiation of different environmental factors had different in optimal fitting model. Soil organic matter with the pure nugget effect, however, other environmental factors had spatial autocorrelation between 6 meters and 31 meters. There are stability of time in the process of the variation of environmental factors. And most of the spatial differentiation of environmental factors are mainly affected by regulation of random factors. Only spatial 
differentiation of soil water content was regulated by structural factors in 2013. Overall, soil mites present inconsistently in the spatial heterogeneity of community and the level of species, and first of it had more stronger stability of time in spatial heterogeneity, however, another one had more strong dynamic characteristics of spatial heterogeneity. Environmental factors also had certain spatial heterogeneity, but they performed the difference in soil mite community and species of mites, space differentiation is regulated by random factors.

Soil mite community has a positive or negative correlation between richness of mite species and environmental factors in a variety of scale space, but only a few species and environmental factors have a significant positive space effect. There were 23 and 21 pair of species possess striking positive correlation among species in 2012 and 2013, respectively. But no significant negative correlation was founded in species. The result is suggesting that there are some effects for soil animals spatial variation in the soil $\mathrm{PH}$, organic matter, water content, litter moisture content and dry weight in 2012,respectively. However, soil PH value had great relevance between soil water content and soil animal differentiation in 2013, of which the soil PH value have an particular effect in soil mite species differentiation, soil PH generate an effect directly or indirectly on the distribution of soil animals(Salmon et al., 1999). Most likely to decide that the availability of soil nutrition which is related to the formation of chemical, concentration and substrate. It shows an effect directly or indirectly on soil microbial community structure(Jiang et al., 2015). On the earth's surface litter and microorganisms is one of the main food source of soil mites, which is regulated from bottom to top, and have an effect on spatial differentiation of soil mites indirectly(Colea et al., 2005).

\section{Conclusions}

Soil mite community, most species of mites and multi-scale had a significant spatial auto-correlation, and forming a pattern of plaque cluster, but the level of community was stronger than the levels of species spatial heterogeneity. The correlate distance of spatial auto-correlation of environmental factors was greater than the correlate distance of mite species and mite communities. Soil mite community, some species richness of mite and environmental factors hada significant positive correlation. Among a few species of mites had a remarkable positive correlation, and the environmental factors (especially the soil $\mathrm{PH}$ value) might play an important role in regulating the species of mites.

\section{Acknowledgments}

The project was financially supported by the auspices of National Natural Science Foundation of China (No. 41101049, 41471037, 41371072, 41430857), Distinguished Young Scholar of Harbin Normal University (No. KGB201204), University Nursing Program for Young Scholars with Creative Talents in Heilongjiang Province (No, UNPYSCT-2015054) and Excellent Youth Scholars of Northeast Institute of Geography and Agroecology, Chinese Academy of Sciences (No. DLSYQ2012004). Thanks for the help from Ping He and Qingming Zhai who did the investigation of outside and the experiment of indoor. Appreciate to Donghui $\mathrm{Wu}$ gave an advice and directed in writing the papers. Thanks to the support of facilities and sample land of Maoer mountain.

\section{References}

[1] J. J. Jiménez, T. Decaëns, E. Amézquita, I. Rao and R. J. Thomas, "Short-range spatial variability of soil physico-chemical variables related to earthworm clustering in a neotropical gallery forest", Soil Biology and Biochemistry, vol. 43, no. 5, (2011), pp. 1071-1080.

[2] C. H. Ettema and D. A. Wardle, "Spatial soil ecology", Trends in Ecology \& Evolution, vol. 17, no. 4, (2011), pp. 177-183.

[3] M. G. López, J. B. Jesús, D. Trigo, R. Fernández, M. Novo and D. J. D. Cosín, "Relationships among spatial distribution of soil microarthropods, earthworm species and soil properties", Pedobiologia, vol. 
53, no. 6, (2010), pp. 381-389.

[4] R. Ojala and V. Huhta, "Dispersal of microarthropods in forest soil", Pedobiologia, vol. 45, no. 5, (2001), pp. 443-450.

[5] M. X. Gao, D. Liu, D. H. Wu and X. P. Zhang, "Spatial autocorrelation of aboveground and belowground mite communities in farmland of the Sanjiang Plain”, Acta Pedologica Sinica, vol. 51, no. 6, (2014), pp. 163-171.

[6] M. X. Gao, D. Liu, X. P. Zhang and D. H. Wu, "Spatial relationsips between the abundance of aboveground and belowground soil mite communities, and environmental factors in a farmland on the Sanjiang Plain, China”, Acta Ecologica Sinica, vol. 36, no. 6, (2015), pp. 1-11.

[7] M. Ingimarsdóttir, T. Caruso, J. Ripa, Ó. B. Magnúsdóttir, M. Migliorini and K. Hedlund, "Primary assembly of soil communities: disentangling the effect of dispersal and local environment", Oecologia, vol. 170, no. 3, (2012), pp. 745-754.

[8] M. A. Minor, "Spatial patterns and local diversity in soil oribatid mites (Acari: Oribatida) in three pine plantation forests", European Journal of Soil Biology, vol. 47, no. 2, (2011), pp. 122-128.

[9] G. W. Krantz and D. E. Walter, "A manual of Acarology", Texas Tech University Press, Lubbock, (2009).

[10] D. E. Walter and H. C. Proctor, "Mites in Soil", CD-ROM, Collingswood, CSIRO Publishing, (2001)

[11] Z. Q. Wang, "Statistics and its application in ecology", Science Press, (1999).

[12] M. X.Gao, P. He, D. Liu, X. P. Zhang and D. H. Wu, "Relative roles of spatial factors, environmental filtering and biotic interactions in fine-scale structuring of a soil mite community", Soil Biology and Biochemistry, vol. 79, (2014), pp. 68-77.

[13] S. Salmon and J. F. Ponge, "Distribution of Heteromurus nitidus (Hexapoda, Collembola) according to soil acidity: interactions with earthworms and predator pressure", Soil Biology \& Biochemistry, vol. 31, (1999), pp. 1161-1170.

[14] X. J. Jiang, X. Y. Hou, X. Zhou, X. P. Xin, A. Wright and Z. J. Jia, "pH regulates key players of nitrification in paddy soils", Soil Biology \& Biochemistry, vol. 81, (2015), pp. 9-16.

[15] L. Colea, S. M. Buckland and R. D. Bardgett, "Relating microarthropod community structure and diversity to soil fertility manipulations in temperate grassland", Soil Biology and Biochemistry, vol. 37, (2005), pp. 1707-1717. 